\title{
Faktor Risiko Terjadinya Persalinan Prematur
}

\author{
Risk Factors of Preterm Labor \\ Panada Sedianing Drastita ${ }^{1}$, Gatut Hardianto ${ }^{2}$, Farida Fitriana ${ }^{3}$, Martono Tri \\ Utomo $^{4}$ \\ ${ }^{1,3}$ Program Studi S1 Kebidanan Fakultas Kedokteran Universitas Airlangga \\ ${ }^{2}$ Departemen Obstetri dan Ginekologi Fakultas kedokteran Universitas Airlangga \\ ${ }^{4}$ Departemen Kesehatan Anak Fakultas Kedokteran Universitas Airlangga \\ 1Email : panada.sedianing.stita-2017@fk.unair.ac.id
}

\begin{abstract}
ABSTRAK
Persalinan prematur merupakan persalinan terlalu dini yang terjadi pada usia kehamilan setelah 20 minggu dan sebelum 37 minggu. Pada tahun 2016, Indonesia berada pada peringkat 7 dengan angka kematian balita tertinggi yang diakibatkan oleh komplikasi kelahiran prematur. Penelitian ini memiliki tujuan untuk menganalisis hubungan faktor- faktor risiko terjadinya persalinan prematur di RSUD Wahidin Sudiro Husodo Mojokerto. Penelitian ini dilaksanakan di bulan Januari-Juni pada tahun 2021. Metode penelitian analitik observasional dengan desain case coontrol. Hasil penelitian yang dilakukan dari hasil uji analisa statistika didapatkan nilai p usia ( $\mathrm{p}=0,005)$; anemia ( $\mathrm{p}=0,018)$; KPD ( $\mathrm{p}=0.009)$, riwayat persalinan premature sebelumnya $(\mathrm{p}=0,496)$. Kesimpulan yang didapatkan dari hasil penelitian ini yaitu usia, anemia, dan KPD terdapat hubungan signifikan dengan proses terjadinya persalinan premature secara statistika. Sedangkan pada penelitian ini tidak didapatkan hubungan antara riwayat persalinan premature dengan terjadinya persalinan premature pada kehamilan berikutnya.
\end{abstract}

Kata kunci: Persalinan Prematur, Usia, Anemia, KPD, Riwayat Persalinan Premature Sebelumnya

\section{ABSTRACT}

Preterm labor is an early delivery that occurs at gestational age after 20 weeks and before 37 weeks. In 2016, Indonesia was ranked $7^{\text {th }}$ with the highest number of toddler deaths caused by compilations of premature birth. This study aims to analyze the relationship of risk factors dor preterm labor at RSU Dr. Wahidin Sudiro Husodo Mojokerto. The study was held from January until June in 2021. Research Method used analytic observasional with case control design. The instruments used is medical records. Analyse data used bivariate with Chi Square. The result age $p=0$,005); anemia ( $p=0,018) ; \operatorname{PPROM}(p=0,009)$; and previous preterm labor $(p=0,49)$. The conclusions that age, anemia, and PPROM there are significant relationship with preterm labor statiscally. In this study there was no relationship between previous preterm labor with occurance of preterm labor in next pregnancies.

Keyword: Preterm Labor, Age, Anemia, PPROM, Previous Preterm Labor

\section{PENDAHULUAN}

Persalinan prematur merupakan persalinan terlalu dini yang mana terjadi pada usia kehamilan lebih dari 20 minggu dan sebelum 37 minggu (American College of Obstetrians and Gynecologist, 2016). Secara Global angka kelahiran prematur pada tahun 2000 hingga tahun 2014 mengalami kenaikan sebesar 8,5\% (Chawanpaiboon et al., 2019). Selain itu berdasarkan Data global, sebesar $16 \%$ kematian balita disebabkan oleh kelahiran prematur dan menyebabkan kematian 
bayi baru lahir sebesar 35\% premature yaitu riwayat kelahiran (Chawanpaiboon et al., 2019). prematur, berat badan kurang, obseitas,

Pada tahun 2010 Indonesia masuk ke dalam peringkat 9 di dunia dengan persalinan prematur sejumlah 15,5 kasus per 100 kelahiran hidup (Blencowe et al., 2013). Pada Tahun 2014 Indonesia masuk peringkat 5 dari 10 negara dengan angka kelahiran premature tertinggi dengan estimasi jumlah sebanyak 527.672 atau sebesar 10,4\% dari jumlah kelahiran hidup (Chawanpaiboon et al., 2019). Pada tahun 2016, Indonesia berada di peringkat 7 dengan angka kematian balita tertinggi yang diakibatkan oleh komplikasi dari kelahiran premature (Chawanpaiboon et al., 2019).

Berdasarkan Data Badan Pusat Statistika Indonesia pada wilayah Jawa Timur tahun 2018 didapatkan sebesar $3,75 \%$ bayi lahir dengan BBLR. Meskipun BBLR tidak sepenuhnya mewakili angka kelahiran prematur seutuhnya. Studi Pendahuluan yang telah dilakukan di RSUD Wahidin Sudiro Husodo Mojokerto didapatkan angka kelahiran prematur pada tahun 2020 sisaptkan sebesar $10,3 \%$ dari angka kelahiran hidup.

Sejumlah faktor risiko yang dikaitkan dengan terjadinya kelahiran diabetes, hipertensi, merokok, infeksi, usia ibu, genetika, kehamilan multijanin, jarak kehamilan yang terlalu berdekatan, gangguan plasenta, dan KPD premature (Butali et al., 2016). Sebuah penelitian yang dilakukan di Ardabil, Iran menyatakan bahwa riwayat kelahiran prematur, hipertensi, preeklamsia, ketuban pecah dini, oligohidramnion, bercak/perdarahan, infeksi saluran kemih, hipermesis gravidarum, status sosial yang rendah, dan tekanan darah diastolik yang rendah diidentifikasikan sebagai faktor risiko terjadinya kelahiran premature (Alijahan et al., 2014).

Berdasarkan data data tersebut Kejadian persalinan prematur masih menjadi perhatian yang sangat besar karena berkontribusi pada mortalitas dan mobiditas ibu dan bayi seara signifikan. Selain itu persalinan prematur juga dapat berdampak pada komplikasi yang menyebabkan mortalitas pada usia balita. Pentingnya penelitian mengenai faktor risiko terjadinya persalinan prematur berfungsi untuk menganalisis faktor apa saja yang menyebabkan persalinan prematur. Sehingga tenaga kesehatan 
dapat melakukan deteksi dini terhadap penyebab persalinan prematur serta meningkatkan perhatian lebih kepada ibu yang memiliki faktor risiko terjadinya persalinan prematur. Dengan memperhatikan faktor-faktor risiko yang menyebabkan persalinan prematur menjadi upaya preventif untuk menurunkan angka kejadian persalinan premature sehingga diharapkan dapat menurunkan angka mortalitas dan morbiditas pada bayi.

\section{METODE PENELITIAN}

Penelitian ini menggunakan sebuah desain penelitian analitik obsevasional rancangan case control secara "retrospective". Penelitian ini dilakukan di Rumah Sakit Umum Wahidin Sudiro Husodo Kota Mojokerto pada bulan Januari-Juni 2021. Variabel terikat (Dependen) yaitu ibu yang melahirkan secara prematur. Variabel bebas (Independen) dalam penelitian ini yaitu usia ibu, anemia, KPD, riwayat prematur sebelumnya. Pada penelitian yang dilakukan ini populasi kasus menggunakan ibu yang melahirkan prematur. Sedangkan, dalam penelitian ini ibu yang melahirkan aterm sebagai populasi kontrol. Perhitungan besar sampel menggunakan rumus Lemeshow diperoleh dari sampel minimal kelompok yaitu 85 sampel dengan perbandingan 1:1 dengan total sampel seluruh sebanyak 170 sampel. Seluruh data yang digunakan diambil menggunakan data rekam medis tahun 2019-2020.

\section{HASIL DAN PEMBAHASAN}

\section{Analisis Secara Univariat}

Tabel 1. Frekuensi berdasarkan usia responden

\begin{tabular}{lcc}
\multicolumn{1}{c}{ responden } & $\mathrm{n}$ & $\%$ \\
\hline \multicolumn{1}{c}{ Usia } & 52 & 30,59 \\
uerisiko (usia <20 tahun \& $>35$ tahun) & & \\
$\begin{array}{l}\text { Reproduksi (usia 20 tahun- } \\
\text { usia 35 tahun) }\end{array}$ & 118 & 69,41 \\
Jumlah & 170 & 100 \\
\hline
\end{tabular}

Berdasarkan tabel 1 menunjukkan hamoir separuhnya $(30,59 \%$ atau 52 responden) berada pada usia berisiko (usia $<20$ tahun dan usia >35 tahun) dan sebagian besar $(69,41 \%$ atau 118 responden) berada pada usia reproduksi (usia 20 tahun - 35 tahun).

Tabel 2. Frekuensi responden yang mengalami anemia

\begin{tabular}{lcc}
\hline \multicolumn{1}{c}{ Anemia } & $\mathrm{N}$ & $\%$ \\
\hline Iya & 16 & 9,41 \\
Tidak & 154 & 90,59 \\
Jumlah & 170 & 100 \\
\hline
\end{tabular}


Berdasrakan Tabel 2. Menunjukkan sebagian kecil $(9,41 \%$ atau 16 orang ) mengalami anemia dan hampir seluruhnya $(90,59 \%$ atau 154 responden) tidak anemia.

Tabel 3. Frekuensi responden yang

\begin{tabular}{lcc}
\multicolumn{3}{c}{ mengalami KPD } \\
\hline \multicolumn{1}{c}{ KPD } & $\mathrm{N}$ & $\%$ \\
\hline Iya & 30 & 17,65 \\
Tidak & 140 & 82,35 \\
Jumlah & 170 & 100 \\
\hline
\end{tabular}

Berdasarkan Tabel 3.

Didapatkan sebagian kecil $(17,65 \%$ atau 30 orang) mengalami KPD dan sebagian besar $(82,35 \%$ atau 140 orang) tidak KPD.

Tabel 4. Frekuensi responden yang mempunyai riwayat persalinan prematur sebelumnya

\begin{tabular}{lcc}
\multicolumn{3}{c}{ prematur sebelumnya } \\
\multicolumn{1}{c}{$\begin{array}{c}\text { Riwayat persalinan } \\
\text { prematur sebelumnya }\end{array}$} & $\mathrm{n}$ & $\%$ \\
\hline Ada & 9 & 5,3 \\
Tidak & 161 & 94,7 \\
Jumlah & 170 & 100 \\
\hline
\end{tabular}

Berdasarkan Tabel 4.

Didapatkan hanya sebagian kecil $(5,3 \%$ atau 9 responden) mempunyai riwayat persalinan prematur sebelumnya dan pada tabel tersebut menunjukkan bahwa hampir seluruhnya $(94,7 \%$ atau 161 responden) tidak mempunyai riwayat persalinan premature sebelumnya.

\section{Analisis Secara Bivariat}

Tabel 5. Analisis hubungan usia dengan terjadinya persalinan prematur menggunakan Chi Square.

\begin{tabular}{lccccccc}
\hline \multicolumn{1}{c}{ Usia } & \multicolumn{2}{c}{ Premature } & \multicolumn{2}{c}{ Aterm } & Total & P & OR \\
& $\mathrm{n}$ & $\%$ & $\mathrm{n}$ & $\%$ & & & \\
\hline Risk & 35 & 41,2 & 17 & 20 & $52(30,6 \%)$ & & \\
No Risk & 50 & 58,8 & 68 & 80 & $118(69,4 \%)$ & 0,005 & 2,8 \\
Total & 85 & 100 & 85 & 100 & $170(100 \%)$ & & \\
\hline
\end{tabular}

$(95 \%$ CI : $1,412-5,554)$

Berdasarkan Tabel 5. Setelah dilakukan analisis bivariat menggunakan Chi Square didapatkan bahwa ibu bersalin premature yang berada pada usia berisiko (usia $<20$ tahun dan usia >35 tahun) sebanyak (35 responden atau 41,2\%) dan pada tabel tersebut didapatkan jumlah ibu bersalin aterm pada usia reproduksi (usia 20 tahun - 35 tahun) sebanyak (17 responden atau $20 \%$ ). 
Selanjutnya pada tabel tersebut menunjukkan angka P-Value sebesar 0,005 yang mana nilai $\mathrm{p}<0,05$ sehingga mempunyai arti bahwa usia ibu memilki hubungan yang bermakna secara statistika dengan terjadinya persalinan prematur. Pada perhitungan analisis pada tabel tersebut menunjukkan nilai OR (Odds ratio) sebesar 2,8. Nilai tersebut memiliki makna bahwa ibu dengan usia berisiko (usia $<20$ tahun dan usia >35 tahun) mempunyai kemungkinan risiko sebesar 2,8 kali lebih besar daripada ibu yang berada pada usia reproduksi (usia 20 tahun usia 35 tahun) mengalami persalinan prematur.

Sebuah penelitian yang dilakukan oleh (Mutmainah \& Rositawati, 2015) menyatakan hal serupa bahwa usia ibu berisiko (usia $<20$ tahun dan usia >35 tahun) mempunyai hubungan bermakna dengan terjadinya persalinan prematur. Pada usia berisiko memiliki risiko hingga 3 kali lebih besar dibandingkan usia reproduksi (Ningrum et al., 2017). Sejalan dengan teori yang menyatakan bahwa kondisi psikis, fisik serta pemenuhan gizi dan nutrisi pada kehamilan usia kurang dari 20 tahun masih terbilang kurang. Selain itu, Menurut (Prawirohardjo, 2010), Munculnya penyakit seperti hipertensi atau diabetes melitus yang akan mengakibatkan terhambatnya makanan janin masuk melalui plasenta terjadi pada usia lebih dari 35 tahun.

Akan tetapi penelitian ini berbanding terbalik dengan penelitian (Rahmawati, 2013)dan (Restiningsih, 2012) menunjukkan tidak terdapat hubungan antara usia dengan terjadinya persalinan prematur dikarenakan persalinan prematur bersifat mutifaktorial yaitu memiliki keterikatan anatar faktor satu dengan faktor lain yang menyebabkan terjadinya persalinan prematur.

Tabel 6. Analisis Chi Square anemia dengan terjadinya persalinan premature.

\begin{tabular}{llllllll}
\hline \multirow{2}{*}{ Anemia } & \multicolumn{2}{l}{ Prematur } & \multicolumn{2}{l}{ Aterm } & Total & P & OR \\
& $\mathrm{n}$ & $\%$ & $\mathrm{n}$ & $\%$ & & & \\
\hline Anemia & 13 & 15,3 & 3 & 3,5 & $16(9,4 \%)$ & & \\
Tidak anemia & 72 & 84,7 & 82 & 96,5 & $154(90,6 \%)$ & 0,018 & 4,9 \\
jumlah & 85 & 100 & 85 & 100 & $170(100 \%)$ & & \\
\hline
\end{tabular}


$(95 \%$ CI $: 1,352-18,012)$

\begin{abstract}
Berdasarkan Tabel 6. Yang dilakukan dengan analisis bivariat menggunakan Chi Square diketahui bahwa ibu bersalin prematur yang mengalami anemia sebanyak 13 responden $(15,3 \%)$ sedangkan yang tidak mengalami anemia hanya 3 responden $(3,5 \%)$.
\end{abstract}

Pada tabel tersebut menunjukkan nilai P-Value pada hasil tersebut sebesar 0,018 dimana nilai $p$ kurang dari 0,05 mempunyai makna bahwa anemia memiliki hubungan dengan terjadinya persalinan prematur. Pada penelitian ini diketahui OR (Odds Ratio) didapatkan nilai sebesar 4,9. Sehingga ibu hamil dengan anemia memiliki kemungkinan risiko sebesar 4,9 kali lebih besar mengalami persalinan prematur dibandingkan dengan ibu yang tidak anemia.

Penelitian (Ulfa et al., 2018) dan (Ningrum et al., 2017) menyatakan hal yang sama bahwa terjadinya persalinan prematur dikaitkan dengan anemia. Penelitian (Rahmawati, 2013) menyebutkan bahwasanya anemia mempunyai risiko 3 kali lebih tinggi menyebabkan terjadinya persalinan premature. Kadar hemoglobin yang rendah akan mengakibatkan kekurangan suplai oksigen pada jaringan palsenta sehingga menyebabkan terjajidnya hipoksia kronis yang menginduksi stress pada janin dan ibu. Hal tersebut akan mengakibatkan kerusakan eritrosit dan mengganggu sirkulasi utero plasenta serta merusak fetal maternal dan memicu terjadinya persalinan prematur (Ulfa et al., 2018)

Bertolak belakang dengan penelitian (Maita, 2012) dan (Zhang et al., 2012) yang menyatakan bahwa terjadinya persalinan premature tidak memiliki hubungan sebab akibat dengan anemia. Penyebab tidak aadanya hubungan tersebut mungkin dapat diakaibatkan oleh tingkat karakteristik pengetahuan ibu yang berbeda. Tingkat pengetahuan ibu mempengaruhi pola piker dalam menjaga kehamilan (Eliza et al., 2017).

Anemia menyebabkan penurunan jumlah sel darah merah yang menyebabkan berkurangnya kemampuan metabolisme tubuh ibu dan mengganggu pertumbuhan janin dalam rahim yang dapat berdampak pada persalinan prematur sehingga dibutuhkan tambahan lebih zat besi yang penting untuk membentuk sel 
darah merah janin dan plasenta

(Cunningham et al., 2012).

Tabel 7. Analisis Chi Square KPD dengan terjadinya persalinan premature.

\begin{tabular}{lccccccc}
\hline \multirow{2}{*}{ KPD } & \multicolumn{2}{c}{ Prematur } & \multicolumn{2}{c}{ Aterm } & Total & P & OR \\
& $\mathrm{n}$ & $\%$ & $\mathrm{n}$ & $\%$ & & & \\
\hline Ya & 22 & 25,9 & 8 & 9,4 & $30(17,6 \%)$ & & \\
Tidak & 63 & 74,1 & 77 & 90,6 & $140(82,4 \%)$ & 0,009 & 3,4 \\
Total & 85 & 100 & 85 & 100 & $170(100 \%)$ & & \\
\hline
\end{tabular}

$(95 \%$ CI $: 1,405-8,063)$

Berdasarkan Tabel 7. Setelah dilakukan analisis Chi Square Ibu bersalin premature yang mengalami KPD sebanyak 22 orang atau 25,9\% sedangkan yang tidak mengalami KPD sebanyak 8 orang $(9,4 \%)$.

Pada tabel tersebut menunjukkan hasil $\mathrm{p}$ sebesar 0,009 dimana $\mathrm{p}<0,05$ yang berarti KPD memiliki hubungan yang bermakna secara statistika dalam terjadinya persalinan prematur. Hasil OR (Odds Ratio) yang didpatkan pada uji ini yaitu sebesar 3,361 yang menunjukkan bahwa KPD memiliki risiko mengalami persalinan prematur 3,4 kali lebih tinggi dibandingkan dengan Ibu yang tidak mengalami KPD.

Penelitian (Carolin \& Widiastuti, 2019) dan (Eliza et al., 2017) mempunyai hasil yang berbanding lurus dengan penelitian ini bahwa terjadinya persalinan prematur dihubungkan dengan KPD. KPD mempenagruhi terjadinya persalinan premature dikarenakan selaput ketuban merupakan barrier bayi dalam kandungan. Apabila usia kehamilan $<37$ minggu maka dilakukan pematangan paru terlebih dahulu sebelum dilahirkan (Carolin \& Widiastuti, 2019). Selain itu, terjadinya persalinan premature diakibatkan rangsangan kontraksi uterus yang diakibatkan oleh pecahnya selaput ketuban pada usia kehamilan premature (Mutmainah \& Rositawati, 2015).

Penelitian lain oleh (Amini, 2012) menyatakan bahwa terjaidnya persalinan premature tidak terdapat hubungan dengan KPD. Perbedaan peneliyian tersebut dapat diakibatkan oleh tingkat keteraturan ANC pada ibu hamil. Dimana ANC sendiri memberikan perkiraan masalah 
Kesehatan esensial meliputi pencegahan penyakit, skrining, dan promosi Kesehatan baik Kesehatan fisik maupun mental ibu untuk mencegah terjadinya persalinan premature (Akhtar et al., 2018).
Pada kejadian KPD harus segera dilakukan pertolongan persalinan karena terjadinya penurunan cairan akibat pecahnya ketuban pada usia kehamilan prematur sehingga, harus segera dilahirkan untuk menyelamatkan bayi dan ibunya (Mutiara et al., 2021).

Tabel 8. Analisis Chi Square riwayat persalinan premature dengan terjadinya persalinan premature

\begin{tabular}{lccccccc}
\hline \multirow{2}{*}{ R.pers prematur } & \multicolumn{2}{c}{ Prematur } & \multicolumn{2}{c}{ Aterm } & Total & P & OR \\
& $\mathrm{n}$ & $\%$ & $\mathrm{n}$ & $\%$ & & & \\
\hline Ada & 6 & 7,1 & 3 & 3,5 & $9(5,3 \%)$ & & \\
Tidak & 79 & 92,9 & 82 & 96,5 & $161(94,7 \%)$ & 0,496 & 2,076 \\
Total & 85 & 100 & 85 & 100 & $170(100 \%)$ & & \\
\hline
\end{tabular}

(Confident Interval 95\% : 0,502-8,588)

Berdasarkan hasil analisis uji premature secara statistika tidak bivariat dengan menggunakan Chi berhubungan dengan terjadinya Square didapatkan hasil pada Tabel $8 . \quad$ persalinan premature pada kehamilan yang menunjukkan sebanyak 6 responden atau $7,1 \%$ yang mengalami persalinan prematur mempunyai riwayat persalinan premature pada persalinan sebelumnya. Pada tabel tersebut hanya 3 responden atau $3,5 \%$ bersalin aterm yang memiliki riwayat persalinan prematur sebelumnya.

Selanjutnya, Pada penelitian ini didapatkan nilai P-Value sebesar 0,496 yang mana nilai tersebut menujukkan nilai $\mathrm{p}$ lebih dari 0,05 sehingga selanjutnya.

Penelitian (Maita, 2012) dan (Ariana et al., 2011) menyatakan terjadinya persalinan premature tidak berhubungan dengan riwayat persalinan premature sebelumnya. Penyebab persalinan premature bukan hanya disebabkan oleh satu faktor saja sehingga pada ibu yang mempunyai riwayat persalinan premature sebelumnya belum tentu akan mengalami persalinan premature pada memiliki arti bahwa riwayat persalinan 
kehamilan selanjutnya (Ariana et al., 2011)

Berbanding terbalik dengan hasil penelitian (Díaz-Rodríguez et al., 2021) yang menyatakan persalinan premature memiliki korelasi dengan ibu yang mempunyai riwayat persalinan premature sebelumnya.

\section{SIMPULAN DAN SARAN}

Berdasarkan hasil penelitian yang telah diuraikan diatas dapat ditarik kesimpulan bahwa Usia ibu, Anemia, dan KPD meningkatkan risiko lebih tinggi menyebabkan terjadinya persalinan premature. Sedangkan dari penelitian ini hasil analisis menunjukkan bahwa riwayat persalinan premature sebelumnya menunjukkan tidak berhubungan dengan terjadinya persalinan premature di kehamilan selanjutnya. Saran bagi tenaga kesehatan untuk melakukan skrining/deteksi dini sebelum kehamilan memperhatikan faktor risiko persalinan premature sebagai bentuk preventif dalam menekan angka kejadian persalinan premature.

\section{DAFTAR PUSTAKA}

Akhtar, S., Hussain, M., Majeed, I., \& Afzal, M. (2018). Knowledge Attitude and Practice Regarding
Antenatal Care among Pregnant Women in Rural Area of Lahore. International Journal of Social Sciences and Management, 5(3), 155-162. https://doi.org/10.3126/ijssm.v5 i3.20604

Alijahan, R., Hazrati, S., Mirzarahimi, M., Pourfarzi, F., \& Hadi, P. A. (2014). Prevalence and risk factors associated with preterm birth in Ardabil, Iran. Iranian Journal of Reproductive Medicine, 12(1), 47-56.

American College of Obstetrians and Gynecologist. (2016). PRACTICE BULLETIN: Management of Preterm Labor. 128, e156-e154.

Amini, A. (2012). Analisis Faktorfaktor Yang Berhubungan Dengan Persalinan Prematur Pada Ibu Bersalin Spontan di Rumah sakit PKU Muhammadiyah Kota Yogyakarta tahun 2010-2012. Universitas Aisyiyah, Yogyakarta, 53(9), 1689-1699.

Ariana, D. N., Saryono, \& Kusumawati, E. (2011). Faktor Risiko Kejadian Persalinan Prematur (Studi. Kesehatan, 13. http://jurnal.unimus.ac.id

Blencowe, H., Cousens, S., Chou, D., Oestergaard, M., Say, L., Moller, A. B., Kinney, M., \& Lawn, J. (2013). Born Too Soon: The global epidemiology of 15 million preterm births. Reproductive Health, 10(SUPPL. 1), 1-14. https://doi.org/10.1186/1742- 
4755-10-S1-S2

Butali, A., Ezeaka, C., Ekhaguere, O., Weathers, N., Ladd, J., Fajolu, I., Esezobor, C., Makwe, C., Odusanya, B., Anorlu, R., Adeyemo, W., Iroha, E., EgriOkwaji, M., Adejumo, P., Oyeneyin, L., Abiodun, M., Badejoko, B., \& Ryckman, K. (2016). Characteristics and risk factors of preterm births in a tertiary center in Lagos, Nigeria. Pan African Medical Journal, 24, 1-8. https://doi.org/10.11604/pamj.2 016.24.1.8382

Carolin, B. T., \& Widiastuti, I. (2019). Faktor-Faktor Yang

Berhubungan Dengan Kejadian Persalinan Preterm Di Rumah Sakit Muhammadiyah Taman Puring Kebayoran Baru Jakarta Selatan Periode Januari-Juni Tahun 2017. Jurnal Ilmu Keperawatan Dan Kebidanan Nasional, 1(1), 12.

Chawanpaiboon, S., Vogel, J. P., Moller, A. B., Lumbiganon, P., Petzold, M., Hogan, D., Landoulsi, S., Jampathong, N., Kongwattanakul, K., Laopaiboon, M., Lewis, C., Rattanakanokchai, S., Teng, D. N., Thinkhamrop, J., Watananirun, K., Zhang, J., Zhou, W., \& Gülmezoglu, A. M. (2019). Global, regional, and national estimates of levels of preterm birth in 2014: a systematic review and modelling analysis. The Lancet Global Health, 7(1), e37-e46. https://doi.org/10.1016/S2214109X(18)30451-0
Cunningham, F. G., Leveno, K. K., Bloom, S. L., Haulth, J. C., Rouse, D. J., \& Spong, C. Y. (2012). Obstetri Williams (R. Setia (ed.); 23rd ed.). EGC.

Díaz-Rodríguez, A., Feliz-Matos, L., \& Ruiz Matuk, C. B. (2021). Risk factors associated with preterm birth in the Dominican Republic: a case-control study. BMJ Open, 11(12), e045399. https://doi.org/10.1136/bmjopen -2020-045399

Eliza, E., Nuryani, D. D., \& Rosmiyati, R. (2017). Determinan Persalinan Prematur di RSUD Dr. Abdul Moeloek. Jurnal Kesehatan, $8(2), \quad 305$. https://doi.org/10.26630/jk.v8i2 .491

Maita, L. (2012). Faktor Ibu yang Mempengaruhi Persalinan Prematur di RSUD Arifin Achmad Pekanbar. Jurnal Kesehatan Komunitas, 2(1), 31-34. https://doi.org/10.25311/kesko m.vol2.iss 1.39

Mutiara, V. S., Absari, N., Rahmawati, I., \& Putri, A. (2021). FaktorFaktor Yang Berhubungan Dengan Persalinan Prematur Di Ruang Mawar Rsud Dr. M. Yunus Bengkulu. Profesional Health Journal, 2(2), 205-215.

Mutmainah, \& Rositawati, R. (2015). Faktor-Faktor yang Berhubungan dengan Kejadian Persalinan Prematur di RSUD dr. Adjidarmo Rangkasbitung 
Tahun 2013. Jurnal Obstretika Scientia, 3(2), 22.

Ningrum, N. W., Nurhamidi, \& Yusti. (2017). Hubungan Umur, Paritas dan Kejadian Anemia dengan Kejdian Persalinan Prematur di RSUD Dr. H. Moch. Ansari Saleh Banjarmasin Tahun 2016. Dinamika Kesehatan, 8(1), 149-157.

Prawirohardjo, S. (2010). Buku Acuan Nasional Pelayanan Kesehatan Maternal dan Neonatal. PT. Bina Pustaka Sarwono Prawirohardjo.

Rahmawati, D. (2013). Faktor-faktor yang mempengaruhi terjadinya persalinan preterm di RSUD dr. moewardi surakarta. Fakultas Ilmu Kesehatan Universitas Muhammadiyah Surakarta, 1, $1-17$.

http://eprints.ums.ac.id/24128/1 0/NASKAH_PUBLIKASI.pdf

Restiningsih. (2012). Pengaruh Faktor Karakteristik Ibu Terhadap Kejadian Persalinan Prematur di RSUD Dr. M. Soewandhie Surabaya. Universitas Airlangga.

Ulfa, A., Ariadi, A., \& Elmatris, E. (2018). Hubungan Antara Anemia pada Ibu Hamil dan Kejadian Persalinan Preterm di RSUP M. Djamil Padang Tahun 2013. Jurnal Kesehatan Andalas, $\quad 6(3), \quad 559$. https://doi.org/10.25077/jka.v6i 3.738

Zhang, Y. P., Liu, X. H., Gao, S. H., Wang, J. M., Gu, Y. S., Zhang,
J. Y., Zhou, X., \& Li, Q. X. (2012). Risk Factors for Preterm Birth in Five Maternal and Child Health Hospitals in Beijing. PLoS ONE, 7(12), 1-7. https://doi.org/10.1371/journal. pone. 0052780 